\title{
METAFORICIDADE: \\ UM ASPECTO \\ DO GÊNERO
}

\author{
METAFORICIDAD: UNASPECTO DEL GÉNERO
}

METAPHORICITY: A GENRE-CONSTRAINED ASPECT

\author{
Dalby Dienstbach* \\ Universidade Federal Fluminense
}

\begin{abstract}
RESUMO: O objetivo deste trabalho é avançar nas discussões sobre uma propriedade específica das metáforas que, até hoje, constitui um caso em aberto: a metaforicidade. O que se busca é elaborar uma definição dessa propriedade que seja consistente com postulados correntes sobre as metáforas a partir da teoria conceptual (LAKOFF; JOHNSON, 1980; LAKOFF, 1993) e investigar os fatores (cognitivos e discursivos) responsáveis pela sua determinação. Para tanto, traça-se um panorama crítico de alguns estudos que têm se debruçado sobre essa propriedade nos últimos trinta anos, aproximadamente. Como resultado, chega-se a um conceito amplo de metaforicidade - como sendo a possibilidade de reconhecimento das metáforas como tais -, que toma a noção de gênero como principal base epistemológica. Por fim, discute-se como o conceito de metaforicidade, definido nos termos propostos aqui, se coloca - em termos teóricos e práticos - à disposição de tarefas de identificação e da análise das metáforas no discurso.

PALAVRAS-CHAVE: Metáfora. Metaforicidade. Metáfora adormecida. Gênero discursivo.
\end{abstract}

RESUMEN: El objetivo de este trabajo es discutir una propiedad particular de las metáforas que todavía es un caso abierto: la metaforicidad. Lo que se busca es la elaboración de una definición de esta propiedad coherente con lo que se sabe acerca de las metáforas basada en la teoría conceptual (LAKOFF; JOHNSON, 1980; LAKOFF, 1993), y la investigación de los factores (cognitivos y discursivos) responsables de determinarla. Para eso, se hace un panorama crítico de algunos estudios que han explorado esta propiedad en los últimos treinta años más o menos. Como resultado, se elabora una definición amplia de metaforicidad - como la posibilidad de reconocimiento de las metáforas como tales - que adopta la noción de género como su principal base epistemológica. Por último, se analiza cómo el concepto de metaforicidad propuesto aquí se pone - en términos teóricos y prácticos - a disposición de tareas de identificación de metáforas y su análisis.

PALABRAS CLAVE: Metáfora. Metaforicidad. Metáfora dormida. Género discursivo.

ABSTRACT: This paper is an attempt at moving forward with the discussion of a specific property of metaphors, which still constitutes an open case: the metaphoricity. I seek to draw up a systematic definition of metaphoricity, which can meet current assumptions about metaphors and their nature from the conceptual perspective (LAKOFF; JOHNSON, 1980; LAKOFF, 1993), and explore cognitive and discursive elements that could somehow affect the activation of that property. For these purposes, I give a critical overview of important studies that have been trying to give some account of metaphoricity over the past 20 years, approximately. As a result, I introduce a broad definition of metaphoricity, which adopts the notion of genre as its ultimate epistemological basis. At last, I discuss both theoretical and practical implications of defining metaphoricity in the manners proposed here, especially when it comes to metaphor identification and metaphor analysis.

KEYWORDS: Metaphor. Metaphoricity. Sleeping metaphor. Discourse genre.

* Aluno do Programa de Pós-Graduação em Estudos da Linguagem, da Universidade Federal Fluminense e bolsista da Fundaçãode Amparoà Pesquisa do EstadodoRiode Janeiro.E-mail: dalby@ufrgs.br. 


\section{INTRODUÇãO}

O termo "metaforicidade" tem pululado, de maneira mais ou menos indiscriminada, em uma miríade de investigações a respeito das metáforas desde, pelo menos, o surgimento da teoria conceptual (originalmente, LAKOFF; JOHNSON, 1980). A discussão preliminar de Leone (1980) e o panorama que Müller (2008) traça dos estudos que já fizeram alguma alusão a essa questão dão testemunho disso. Em linhas gerais, podemos dizer que esse termo é geralmente recrutado para dar conta de uma impressão - muitas vezes, nebulosa - do analista de que algumas metáforas seriam "mais metafóricas" do que outras (DUNN, 2011). Para ilustrar isso, consideremos as sentenças em (1) a (3), apresentadas abaixo.

(1) "Amorim faz alerta sobre situação da saúde em Sergipe." (AGÊNCIA SENADO, 2015)

(2) "O Brasil deve, mas está longe de estar quebrado." (SANTAYANNA, 2015)

(3) "Governadores na pindaíba podem colocar pedras no caminho de Temer." (FREIRE, 2016)

As três expressões sublinhadas acima podem ser explicadas, em uma análise simples, como sendo instanciações de uma mesma metáfora conceptual, qual seja. CONDIÇÃO É LOCALIZAÇÃO (GRADY, 1997, p. 286). Ela emerge do nosso entendimento de que o estado das coisas pode ser determinado pelas condições do lugar onde elas se encontram. Do ponto de vista da teoria conceptual (LAKOFF; JOHNSON, 1980; LAKOFF, 1993), portanto, não deve haver dúvidas de que todas essas expressões sejam metafóricas. No entanto, alguém poderia argumentar que elas não são metafóricas na mesma medida. Um olhar mais desconfiado diria que a expressão "[estar] na pindaiba", em (3), parece ser mais nitidamente metafórica do que "a situação da saúde", em (1). Sobre esse ponto, ainda, a metaforicidade de "longe de estar quebrado", em (2), talvez seja a menos fácil de se determinar.

Como pode se deduzir, é inevitável se recorrer a algum prumo para se dar conta dessa sensação de que expressões metafóricas o seriam em diferentes medidas. É em circunstâncias como essa que convém, pois, a noção de metaforicidade. Contudo, apesar da grande recorrência com que esse conceito é utilizado, são poucos - e relativamente incipientes - os estudos que se prestam a definila e explicá-la de maneira realmente sistemática² (por exemplo, BLACK, 1993 [1979]; PAUWELS, 1995; GOATLY, 1997; STEEN, 2004; DUNN, 2011; MÜLLER, 2008). Por causa disso, este trabalho se propõe como mais um esforço de se avançar na discussão sobre essa propriedade particular da linguagem metafórica.

A fim de contribuir, em última análise, para o nosso entendimento geral sobre as metáforas, elabora-se, em um momento inicial, uma definição de metaforicidade capaz de atender, sob a luz da teoria conceptual (LAKOFF; JOHNSON, 1980; LAKOFF, 1993), aos postulados mais correntes sobre a metáfora e a sua natureza. Em seguida, especulam-se quais fatores seriam intervenientes na determinação dessa propriedade, assumindo-se, nesse caso, o gênero (discursivo) como principal base epistemológica de análise. Em última instância, são discutidas algumas consequências, tanto teóricas quanto práticas, de se definir a metaforicidade dentro dos moldes propostos aqui.

\section{UMA DEFINIÇÃO DE METAFORICIDADE}

Em uma discussão sobre a possibilidade de se criar um método de identificação automática de metáforas, Babarczy et al. (2010), em algum momento, chegam à conclusão de que "a definição de 'metaforicidade' é, por si só, problemática" (p. 03, grifo no original). Na verdade, esses autores (2010) não estão preocupados em definir metaforicidade; eles sequer se prestam a quaisquer explicações para

1 Ainda que o uso mais convencionalizado de "situação" possa denotar o estado, condição ou qualidade de algo, o seu sentido mais básico se refere à "localização de um corpo no espaço em relação a um ou vários pontos de referência fora dele; posição” (HOUAISS et al., 2009, p. 1755).

2 Dá testemunho de certa desatenção pela questão da metaforicidade o fato de obras importantes como Metaphor: a practical introduction (KÖVECSES, 2010) e The Cambridge handbook of metaphor and thought (GIBBS, 2008) não reservarem quaisquer parágrafos para discuti-la ou, ainda, de o Glossary of cognitive linguistics (EVANS, 2007) sequer mencioná-la.

3 [These results indicate that the definition of "metaphoricity" is problematic in itself.] 
esse conceito. A sua principal inquietação recai, nesse caso, sobre o fato de os quatro autores não conseguirem chegar a um consenso quanto a serem metafóricas (ou não) algumas das expressões que analisam. Acredita-se que essa inquietação seja algo que todo analista de metáforas já teve (ou ainda tem) que lidar em alguma etapa (ou várias) das suas análises.

Encontra-se uma definição aparentemente descomplicada de metaforicidade no dicionário Oxford (2015), que diz que ela é "o fato ou a qualidade de [algo] ser metafórico"4. Essa explicação parece ser bastante procedente se a compararmos com o sentido de outras palavras morfologicamente semelhantes - ou seja, conjugadas com o sufixo "idade" -, como, por exemplo, "utilidade" (a qualidade de ser útil), "dificuldade" (a qualidade de ser difícil), "literalidade" (a qualidade de ser literal) etc. No entanto, apenas atribuir o epíteto "metaforicidade” à condição (supostamente) absoluta de uma expressão ser metafórica não ajuda a resolver a questão a respeito de as metáforas, por alguma razão, serem metafóricas em diferentes medidas.

Uma explicação um pouco mais sensível ao espectro de metaforicidade que pode marcar a linguagem metafórica seria uma que pode ser formulada a partir de um comentário de Pauwles (1995, p.126), segundo o qual "[...] devemos pensar a metáfora em termos de metaforicidade, isto é, a metáfora como uma questão de grau”. Nesse sentido, pode se definir metaforicidade, basicamente, como sendo o grau em que uma metáfora é metafórica. Essa definição parece ser pertinente na medida em que dá conta, justamente, daquela sensação de que algumas metáforas seriam "mais metafóricas" do que outras.

Da maneira como está formulada, porém, essa definição soa um tanto incompleta, uma vez que insinua que a condição de ser menos ou mais metafórica emergiria apenas da própria expressão. De fato, de um ponto de vista analítico, a explicação de metaforicidade como sendo o grau em que uma metáfora é metafórica dá a impressão de que os fatores que poderiam intervir na sua determinação teriam efeitos somente sobre a linguagem metafórica per se, deixando de fora os seus efeitos, por exemplo, sobre a atenção do falante. No entanto, até onde se entende atualmente, a natureza da metáfora está condicionada a aspectos relativos tanto à linguagem quanto ao pensamento (LAKOFF; JOHNSON, 1980), tanto ao sistema (linguístico/conceptual) quanto ao seu uso individual (STEEN, 2006).

Seja como for, em se levando em consideração os vários estudos que já se ocuparam da questão da metaforicidade (por exemplo, BLACK, 1993 [1979]; PAUWELS, 1995; GOATLY, 1997; STEEN, 2004; MÜLLER, 2008), percebe-se que eles guardam, pelo menos, um ponto em comum. Independentemente dos aspectos que elegem para determiná-la, todos associam essa propriedade, de uma forma ou de outra, com o fato de as metáforas poderem ser percebidas como sendo metáforas. Por conta disso, a definição que se propõe aqui, grosso modo, é a de metaforicidade como sendo a possibilidade de uma metáfora ser reconhecida como tal - sejam quais forem os fatores que estariam por trás dessa possibilidade.

Essa definição, por sua vez, busca contemplar tantos aspectos - discursivos ou puramente cognitivos, coletivos ou estritamente individuais - quantos possam intervir na percepção das metáforas como sendo metáforas. Ela não privilegia ou se fecha a quaisquer elementos que venham a participar da realização da linguagem metafórica, que incluiriam desde a condição da própria expressão no sistema linguístico/conceptual até as particularidades do contexto que marcam o seu uso e a disposição do falante para reconhecêla. E os efeitos de cada um desses elementos teriam igual peso na determinação da sua metaforicidade. É essa a explicação, pois, - de metaforicidade como sendo a possibilidade de reconhecimento das metáforas como tais - que este trabalho assume de uma vez por todas. Serão explorados, a partir de agora, os aspectos que podem intervir na sua determinação.

4 [metaphoricity noun (is) the fact or quality of being metaphorical.]

5 [One should think (of metaphor) in terms of metaphoricity, i.e. metaphor as a matter of degree.] 


\section{A DETERMINAÇÃO DA METAFORICIDADE}

Uma explicação bastante comum sobre o que determinaria a metaforicidade da linguagem metafórica está representada pela noção de metáfora morta ${ }^{6}$. A sua versão mais conhecida é geralmente atribuída a Black (1993 [1979]), de acordo com quem "[...] a única classificação consistente [de metáforas] está fundamentada na oposição elementar - ela mesma expressa metaforicamente - entre metáforas mortas e vivas" (p. 25, grifos no original). A partir dessa explicação, portanto, a metaforicidade se traduziria, essencialmente, como uma suposta vitalidade da linguagem metafórica.

Em linhas gerais, a visão de metaforicidade com base na vitalidade das metáforas (BLACK, 1993 [1979]) assinala como vivas ou "ativas" [active] (p. 25) as metáforas (muito) transparentes, que ainda podem ser reconhecidas como metafóricas. Seria o caso, por exemplo, da expressão "[estar] na pindaíba", em (3), acima. As expressões que são muito opacas a ponto de não poderem mais ser reconhecidas como tais são ditas mortas ou "extintas" [extinct] (loc. cit.). Analise-se, mais uma vez, a construção "a situação da saúde", em (1). Além do mais, para as metáforas cujo reconhecimento é possível, porém, não imediatamente - como, por exemplo, "longe de estar quebrado", em (2) -, propõe-se a categoria "dormente" [dorment] (loc. cit.).

Essa classificação de metáforas (em mortas ou vivas) (BLACK, 1993 [1979]) atribui a metaforicidade, basicamente, a um aspecto específico da expressão metafórica, que é a sua convencionalidade ${ }^{8}$ (no sistema linguístico). Se a expressão já está suficientemente convencionalizada, de modo que a sua realização seja automática, ela está morta. Se, no caso contrário, ela é criativa e não se realizaria de maneira automática, ela ainda está viva. Nesse sentido, o parâmetro da convencionalidade considera irrelevante o uso concreto dessas expressões. Ou seja, para uma visão de metáfora morta (BLACK, 1993 [1979]), “[...] uma metáfora ou está ativa ou está dormente ou está extinta. Ela não pode estar extinta em um contexto e ativa em outro contexto"s (MÜLLER, 2008, p. 188, grifos no original).

No entanto, quando se parte de uma visão de metáfora focada na sua representação mental - tal como a teoria conceptual (LAKOFF; JOHNSON, 1980; LAKOFF, 1993) -, subordinar a metaforicidade apenas à convencionalidade da expressão metafórica no sistema linguístico se torna insuficiente. $\mathrm{O}$ fato de uma expressão estar convencionalizada no sistema (de quem quer que seja) não significa que ela seja necessariamente opaca à nossa percepção individual - pelo menos, não o tempo todo. Um falante que soubesse a história da língua, por exemplo, poderia interpretar a expressão "a situação da saúde" imediatamente como metafórica se trouxesse à mente o sentido mais básico ${ }^{10}$ de "situação".

Afinal de contas, a condição de ser menos ou mais metafórico também se determina, por exemplo, pelo olhar do falante e pelo seu processamento individual das metáforas. Segundo Pauwels (1995), "as experiências dos falantes podem ser muito diferentes", o que acarreta, fatalmente, alguma disparidade entre os seus sistemas linguísticos/conceptuais; "logo, a saliência das metáforas também pode ser diferente para cada um deles"11 (p. 126). Metáforas que fossem "muito metafóricas" para um certo falante, em um certo contexto, poderiam passar despercebidas por outro (ou pelo mesmo) falante, em outro contexto. E há, ainda, as expressões cuja condição de ser metafórica somente poderia ser recuperada pelo olhar treinado de um especialista em metáforas.

Algo que deve ser observado aqui, a propósito, é que, nos moldes da teoria conceptual (LAKOFF; JOHNSON, 1980; LAKOFF, 1993), uma explicação consistente sobre as metáforas, a sua natureza e o seu funcionamento precisa conseguir articular, em uma maior

\footnotetext{
6 Considerações feitas por Richards (1936) a respeito das “metáforas mortas” [dead metaphors] (p. 101-102) sugerem que essa noção já atravessa quase um século.

7 [The only entrenched classification is grounded in the trite opposition - itself expressed metaphorically - between dead and live metaphors.]

8 Uma explicação para convencionalidade pode ser a interpretação feita a partir dos sentidos lexicais automaticamente associados às formas, antes que quaisquer inferências externas, baseadas em dados contextuais, possam ser derivadas (GIORA, 1997).

9 [A (metaphorical) expression is either active or dormant or extinct; it cannot be dormant in one context and active in another one.]

10 Por sentido básico, entende-se, aqui, o sentido mais concreto, mais corpóreo, mais preciso e mais antigo de um item lexical qualquer (PRAGGLEJAZ, 2007).

11 [The experiences of its members may differ substantially, which is why salience (of a metaphor), too, may differ for individual language users.]
} 
medida possível, as duas dimensões em que elas se realizam (STEEN, 2006): uma do sistema - social, offline e descontextualizada -, e outra do seu uso - individual, online e situada. Logo, uma explicação de metaforicidade, dentro desse contexto, também deve dar conta de elementos que se referem tanto ao sistema (linguístico/conceptual) em que as metáforas estão inscritas quanto ao uso individual desse sistema por cada falante. O que se presume aqui, então, é que uma abordagem discursiva da metaforicidade (por exemplo, MÜLLER, 2008) seria mais capaz de atender a esse requisito.

Introduzido por Goatly (1997), o conceito de "metáfora adormecida" [sleeping metaphor] (p. 30) representa uma explicação de metaforicidade que consegue dar conta da exigência por uma abordagem mais fenomenológica dessa propriedade. Essa explicação argumenta, grosso modo, que "a metaforicidade de uma metáfora falada ou escrita está inserida no curso da fala, da escrita e da consciência $^{12 "}$ (MÜLLER, 2008, p. 36). Em outras palavras, a possibilidade de uma metáfora ser reconhecida como tal se determina antes pelos (muitos) aspectos que marcam o contexto do seu uso concreto do que somente pela sua condição no sistema linguístico/conceptual (de quem quer seja). Para exemplificar essa explicação, considere-se a sentença em (4) abaixo.

(4) “Atlético Mineiro [está] voando em campo, literalmente." (GARAMBONE, 2013 ${ }^{13}$ )

A expressão "voando em campo" pode ser explicada como uma atualização de uma metáfora conceptual que emerge do nosso entendimento de TEMPO em termos de um OBJETO que se move no espaço (LAKOFF; JOHNSON, 1980, p. 42). Nesse caso, porque os jogadores do time em questão fazem jogadas rápidas, por exemplo, diz-se que eles estão metaforicamente voando na partida. Essa metáfora constitui uma expressão bastante convencionalizada - conforme atestam alguns dicionários gerais da língua portuguesa (por exemplo, FERREIRA, 2004; HOUAISS et al., 2009, p. 1956). A partir de uma visão de metaforicidade com base na vitalidade das metáforas (BLACK, 1993 [1979]); portanto, essa expressão estaria morta.

No entanto, ao se considerar todo o contexto (sintático) em que a expressão "voando em campo" está sendo usada, em (4), a sua classificação como morta deixa de ser tão óbvia. A ocorrência (supostamente equivocada ${ }^{14}$ ) do advérbio "literalmente" parece poder colocar à luz da nossa percepção a condição de "voando em campo" como sendo uma metáfora, já que torna evidente a incongruência semântica dessa sentença - afinal de contas, jogadores não podem realmente voar. Outro exemplo de como certos elementos (verbais) afetariam a possibilidade de uma metáfora ser reconhecida como tal pode ser verificado ao longo da sentença em (5), apresentada abaixo.

(5) "Por maior que seja o buraco em que você se encontra, pense que, pelo menos, ainda não há terra em cima." (autor desconhecido)

O uso da palavra "buraco", em (5), é uma atualização da metáfora conceptual BOM É PARA CIMA (LAKOFF; JOHNSON, 1980, p. 15). Essa foi a forma que o seu autor escolheu para conceptualizar a noção de problema ou situação adversa, da qual, em geral, somente conseguimos sair com alguma dificuldade. Esse uso soa bastante convencionalizado, o que sugere que a condição de "buraco" como metáfora poderia passar despercebido pela nossa leitura. No entanto, a ocorrência de "terra em cima", no final da sentença, parece colocar em evidência essa condição. Porque faz referência direta ao domínio-fonte PARA BAIXO (PARA CIMA) do mapeamento que sustenta essa metáfora, "buraco" passa a denotar, também, um sentido básico seu, que seria o de cova ou de sepultura e, enfim, o de morte.

Observa-se, então, que, em função de determinado aspecto da sua sequência sintática, o uso metafórico de "buraco", em (5), tem uma metaforicidade bastante particular nesse contexto. Algo que é possível se deduzir, no final das contas, é que uma metáfora que se

12 [The metaphoricity of a spoken or written metaphor [...] is embedded in the flow of speech, writing, and in the flow of consciousness.]

13 Declaração do jornalista Sidney Garambone, em uma rede social virtual, em maio de 2013. Disponível em: <https://twitter.com/Garamba/>. Acesso em: 07 jun. 2016.

14 Em muitos usos, de fato, o termo "literalmente" tem o seu sentido estendido para marcar intensidade, sendo que esses usos contrariam o sentido básico de "literal" como "ao pé da letra" (VEREZA, 2007a). 
julgaria morta - sob uma visão de metaforicidade com base na vitalidade das metáforas (BLACK, 1993 [1979]) -, a depender das circunstâncias em que ocorrer, pode ter grandes chances de ser reconhecida como tal ${ }^{15}$. É isso que justifica, nesse sentido, a escolha por classificar esse tipo de metáfora como adormecida (em vez de morta), pois se acredita que, seja por quaisquer razões e meios que forem, todas elas ainda poderiam ser, de alguma forma e em alguma medida, despertadas.

Aos elementos que são capazes de despertar (ou desautomatizar) metáforas no curso do seu uso, Müller (2008) dá o nome de "recursos de ativação de metaforicidade" [activation devices of metaphoricity] (p. 190). Esses recursos podem ser verbais, como é o caso do uso de "literalmente" e "terra em cima", nas sentenças em (4) e (5), respectivamente, ou pertencer a outras modalidades. Cloiseau (2007), por exemplo, investiga os efeitos de recursos sonoros - mais precisamente, a marcação prosódica - sobre o reconhecimento de metáforas durante a fala. Já Müller (2008), em sua pesquisa, explora de que maneira elementos visuais, tais como gestos e imagens, podem intervir na determinação da metaforicidade das metáforas. Um exemplo claro de recurso não verbal de ativação da metaforicidade aparece na capa (Figura 1) de uma edição de revista Veja (18/04/2007), reproduzida abaixo.

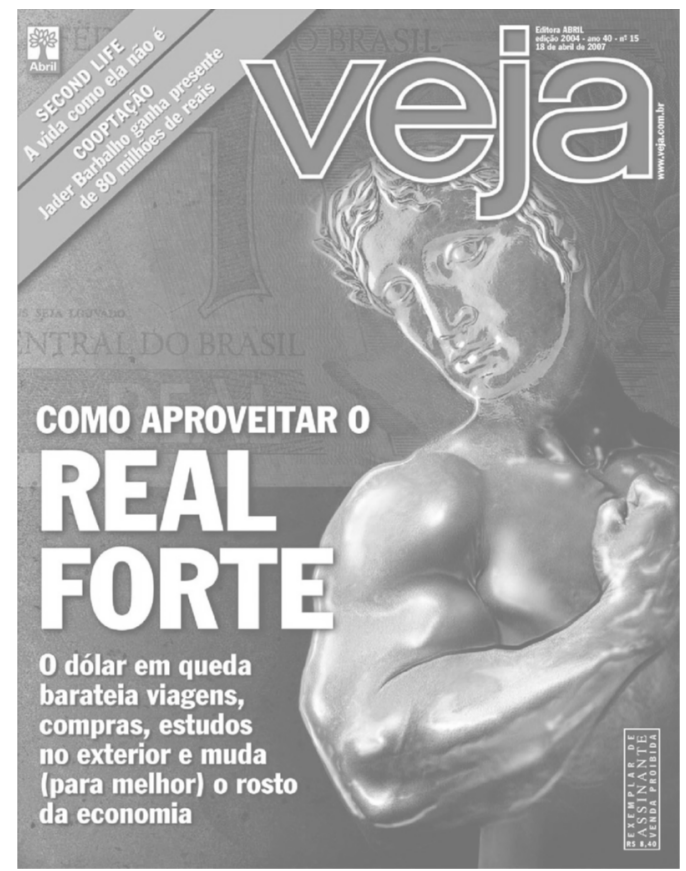

Figura 1: Capa da edição 2004 da revista Veja (18/04/2007)

Fonte: COMO... (2007)

A expressão "real forte", que completa a manchete dessa capa (Figura 1), élicenciada pela metáfora conceptual SISTEMA ABSTRATO É ESTRUTURA FÍSICA (KÖVECSES, 2010, p. 139). Segundo ela, entendemos sistemas abstratos - como, por exemplo, a economia de um país - em termos de uma entidade concreta, como, por exemplo, um prédio ou o corpo humano, pelo que essa expressão comunica, então, quanto mais estável estiver a economia do nosso país, mais metaforicamente forte será a nossa moeda ${ }^{16}$. Essa expressão é bastante convencionalizada (por exemplo, FERREIRA, 2004; HOUAISS et al., 2009, p. 1305), e, por isso, alguém poderia argumentar que ela dificilmente seria reconhecida como metafórica.

Entretanto, a manchete na capa dessa edição de Veja (18/04/2007) está acompanhada por uma reprodução da efígie da República ${ }^{17}$ - que estampa as moedas e cédulas de dinheiro brasileiras - exibindo um braço musculoso e visivelmente forte. Da forma como está

15 É importante se observar que esse postulado - a respeito de uma manipulação da metaforicidade - pressupõe que ambos os sentidos literal e metafórico de uma dada expressão devem, mesmo que em níveis diferentes, estar disponíveis ao falante no momento do seu uso.

16 É interessante se comentar que o uso de "real forte", aqui, atualiza, concomitantemente à respectiva metáfora, uma projeção metonímica, em que o sistema econômico (brasileiro) é conceptualizado em termos da unidade monetária que ele emprega.

17 A efígie da República é a personificação da nação brasileira, representada por uma mulher e inspirada na obra plástica A liberdade guiando o povo [La Liberté guidant le peuple] (DELACROIX, 1830); foi usada como símbolo da Proclamação da República brasileira, em 1889 (BRASIL, 1994). 
reproduzida, essa imagem coloca em franca evidência um elemento específico do domínio-fonte CORPO HUMANO que compõe a metáfora por trás de "real forte". Sendo assim, essa imagem estaria operando como um recurso (não verbal) de ativação da metaforicidade dessa expressão, aumentando as chances de ela ser mais prontamente reconhecida como metafórica.

Com respeito aos recursos de ativação de metaforicidade, entende-se, pois, que os seus efeitos sobre a possibilidade de as metáforas serem reconhecidas como tais percorrem um caminho muito direto. Na verdade, segundo Müller (2008, p. 190, grifo no original),

[...] quanto mais material for utilizado para expressar a sua metaforicidade, mais saliente uma metáfora será para o ouvinte ou leitor, e mais ativa ela estará para o falante ou autor. Metáforas verbais que implicam elaborações, especificações e/ou expressões multimodais são mais salientes - e, por isso, devem ter sido ativadas de modo veemente pelo emissor - do que metáforas sem a mesma carga semântica. ${ }^{18}$

É importante se mencionar, por fim, que, dentro do modelo de metáforas adormecidas (MÜLLER, 2008), a metaforicidade possui algumas características fundamentais. Em primeiro lugar, ela constitui uma propriedade dinâmica das metáforas, uma vez que é dependente do andamento do contexto em que elas ocorrem. Além disso, ela é variável, pois se altera na medida em que o contexto também pode mudar. Ou seja, não se descarta a possibilidade de uma metáfora, que está muito metafórica em certo contexto, passar despercebida em outro contexto. Entende-se, por fim, que a metaforicidade é gradual. Com efeito, tanto a quantidade quanto a qualidade dos recursos para a sua ativação podem ser menor ou maior em cada contexto; sendo assim, "metáfora adormecida" e "metáfora desperta" não constituem categorias fechadas. Elas representariam, em vez disso, pontos extremos de uma escala, com as expressões metafóricas, em cada caso, ocupando uma posição mais próxima de um ou de outro. Em seguida, discute-se uma forma de se compreender as singularidades do contexto capazes de intervir na metaforicidade.

\section{UMA NOÇÃO DE METAFORICIDADE BASEADA NO GÊNERO}

Não é por acaso que os exemplos de recursos de ativação da metaforicidade oferecidos até agora integram tipos muito particulares de discurso: mais exatamente, uma afirmação espontânea, um aforismo humorístico e uma capa de revista semanal. Até onde se sabe, na verdade, metáforas são onipresentes e inevitáveis (LAKOFF; JOHNSON, 1980) e, por isso, podem ocorrer em quaisquer tipos de discurso. No entanto, algo que se argumenta aqui é que não é em quaisquer tipos de discurso que metáforas poderiam - ou, em certos casos, deveriam - ser reconhecidas como tais ${ }^{19}$. Müller (2008, p. 202) observa, por exemplo, que,

[q]uando se consideram as modalidades em que a linguagem se insere, tais indicadores de metaforicidade entram naturalmente em cena. A linguagem falada é sempre corporificada; integra uma combinação multimodal de gestos, posturas, olhares, expressões faciais. Em modalidades públicas de discurso escrito (jornais, revistas, anúncios publicitários, cartazes), a palavra escrita, em geral, vem acompanhada de figuras. ${ }^{20}$

E, se há eventos de uso da linguagem - tais como conversas orais, capas de revista e anúncios publicitários - naturalmente abertos à ocorrência de recursos de ativação de metaforicidade, não é equivocado se afirmar, então, que certos eventos discursivos não assimilariam - pelo menos, não de maneira tão espontânea - o emprego desses elementos. Isso explicaria, em alguma medida, $o$ reconhecimento (por parte de um leitor comum) de muito poucas ou nenhuma metáfora, por exemplo, em bulas de medicamento,

18 [The more material is used to express metaphoricity, the more salient this metaphor is for a listener or reader - and hence the more active it is for a speaker/writer. Verbal metaphors that inspire elaborations, specifications, and/or multimodal expressions are more salient - and hence must have been highly activated in the producer - than metaphors without such a semantic uptake.]

19 Esse argumento, a propósito, já permite se cogitar uma possível relação de determinação mútua entre a metaforicidade e os gêneros (discursivos). Se, por um lado, um dado gênero parece ser capaz de regular o grau de metaforicidade nos respectivos textos, por outro, a metaforicidade típica em uma dada classe de textos poderia servir para caracterizar (cognitivamente) o seu gênero.

20 [When taking into account some of the modalities in which language is embedded, such indicators (of metaphoricity) quite naturally appear on stage. [...] The spoken word is always embodied. It is part and parcel of a multimodal ensemble of gesture, posture, gaze, and facial expression. [...] In public forms of written discourse (newspapers, magazines, advertisements, and billboards), the written word is often accompanied by pictures.] 
manuais de eletrodoméstico e artigos científicos, mesmo que esses textos abriguem tantas (ou mais) metáforas do que conversas orais, capas de revista e anúncios publicitários.

No final das contas, estariam identificados com um alto grau de metaforicidade os tipos de discurso que autorizassem mais meios (ou seja, mais recursos de ativação de metaforicidade) para que as suas metáforas fossem reconhecidas como tais - seja isso porque elas podem ou porque elas devem ser reconhecidas como tais. Os tipos de discurso cujo reconhecimento das suas eventuais metáforas fosse prescindível ou, até mesmo, inconveniente - seja pelas razões que fossem - seriam caracterizados, por sua vez, por uma metaforicidade menor. Isso seria assegurado pela ocorrência escassa ou funcionalmente inócua de recursos de ativação da sua linguagem metafórica.

Deve se comentar, contudo, que, nos moldes da explicação de metaforicidade como dependente do contexto (GOATLY, 1997; MÜLLER, 2008), a determinação da possibilidade de as metáforas serem reconhecidas como tais constitui uma tarefa bastante complexa. Porque a diversidade e as particularidades dos contextos em que as metáforas podem ocorrer são virtualmente infinitas, definir quais fatores realmente afetam a metaforicidade - e em que medida eles a afetam - parece ser impraticável. Decorre disso a necessidade de uma forma de se abordarem sistematicamente os aspectos que caracterizam os diferentes tipos de discurso em que metáforas podem ocorrer. O expediente que esse trabalho propõe é por meio da noção de gênero.

Uma noção de gênero consistente com essa necessidade deve conseguir contemplar os aspectos pertinentes tanto à esfera conceptual quanto à esfera linguística em que as metáforas se ancoram. Nesse sentido, o conceito que se adota aqui é o de gênero como sendo o frame de um evento discursivo, inspirado em postulados de Paltridge (1995) e Steen (2011b) a respeito desse fenômeno. Apesar de curta, essa definição tenta incorporar tantos fatores - discursivos ou puramente cognitivos, coletivos ou estritamente individuais quanto possíveis que tivessem algum efeito sobre a possibilidade de reconhecimento das metáforas como tais.

Ao se assumir o gênero, por um lado, como um evento discursivo, entende-se que ele não está representado somente pelos textos que evoca, senão por todo o acontecimento social em que ocorre esse uso da linguagem. O gênero possui, pois, um caráter sociossemiótico e se estabelece em função de todos os elementos - textuais e contextuais - presentes na sua realização. Em um esquema proposto por Bhatia (2004, p. 11), esses elementos são arranjados em quatro eixos principais ${ }^{21}$ : (i) os “propósitos” [purposes], isto é, os objetivos comunicativos gerais e específicos que orientam o discurso; (ii) o "produto" [products], que é o material textual oral ou escrito evocado no evento; (iii) as "práticas" [practices], que são os procedimentos e processos discursivos; e os "participantes" [players], ou seja, os membros que participam da realização do gênero e as relações entre eles.

Para explicar a representação cognitiva dos elementos que completam um evento discursivo, por outro lado, a definição proposta neste trabalho lança mão da noção de frame, conforme está elaborada por Fillmore (1982). Segundo esse autor (1982), frame consiste em "um sistema [relativamente estável] de conceitos relacionados de tal maneira que, para se entender qualquer um deles, é necessário ter conhecimento de toda a estrutura de que ele faz parte”22 (p. 111). Sendo assim, o gênero seria, em última análise, um esquema abstrato cujos elementos (produtos, práticas, participantes, propósitos etc.) estariam inter-relacionados. O acesso a um ou alguns desses elementos - sejam textuais ou contextuais - faz com que evoquemos conhecimentos e expectativas sobre o todo do evento discursivo.

De fato, em algumas vezes, são os aspetos textuais que revelam de que contexto se trata. Por exemplo, uma pessoa que lê este trabalho deve poder fazer certas inferências sobre a ocupação de quem o escreveu, com que propósitos e em que circunstâncias. Em outras vezes, são aspectos contextuais que anunciam o texto. Uma pessoa que escolhesse frequentar um curso de literatura, por exemplo, poderia criar alguma expectativa a respeito da ocorrência de metáforas nos textos que fossem ser trabalhados durante as aulas. É justamente esse raciocínio que ajuda a explicar, em grande medida, por que um pressuposto de metaforicidade como uma

21 Há paradigmas de análise que sugerem outros arranjos dos elementos do gênero, como, por exemplo, o de Paltridge (1995) - que propõe os planos do texto, da interação e da instituição - e o de Steen (2011b) - que se estrutura nos modelos do texto, do contexto e do código. Apesar das divergências entre esses paradigmas, a opinião sobre os elementos que completam o gênero (enquanto evento discursivo) é motivo de consenso entre eles.

22 [By the term "frame" I have in mind any system of concepts related in such a way that to understand any one of them you have to understand the whole structure in which it fits.] 
propriedade dependente do contexto poderia ser aprimorado como uma teoria de metaforicidade como um aspecto do gênero.

Já se mencionou neste artigo que a alta metaforicidade da linguagem metafórica, promovida pelo uso favorável de recursos da sua ativação, típica de certos eventos discursivos - como, por exemplo, os que incluem poemas -, permite que as suas metáforas sejam frequentemente reconhecidas como tais. Logo, entende-se que a ocorrência efetiva de metáforas se inscreveria no processo de formação do frame do seu gênero (poema) como um aspecto prototípico seu ${ }^{23}$. Em um caso contrário, os poucos ou nenhum recurso de ativação de metaforicidade em outros tipos de discurso - como, por exemplo, um manual de eletrodoméstico - e o consequente não reconhecimento das suas eventuais metáforas fariam com que a ocorrência desse fenômeno não participasse como sendo um traço característico do frame do seu gênero (manual de eletrodoméstico).

Argumenta-se, ainda, que o gênero também estaria por trás da determinação da metaforicidade nos discursos que se identificassem com ele. $\mathrm{O}$ uso do frame de um dado gênero, na ocasião de produção da linguagem, seria responsável por aumentar ou diminuir a possibilidade de reconhecimento das metáforas como tais nos seus respectivos textos. Isso o é porque seriam as expectativas relativas à ocorrência de metáforas - pertinentes ao frame de cada gênero que ora incentivaria, ora constrangeria o uso de recursos de ativação da sua metaforicidade. E essas expectativas derivadas do frame de cada gênero teriam efeitos, também, sobre a nossa percepção das metáforas na ocasião de recepção da linguagem. Pense-se, por exemplo, como as expectativas relativas a um frame de tarefa de identificação de metáforas devem ter afetado a atenção de analistas, como Babarczy et al. (2010), para a ocorrência de metáforas nos textos que eles exploram.

Em síntese, o ponto central que se defende neste estudo está amparado por dois pressupostos principais. Entende-se, em primeiro lugar, que seriam a quantidade e a qualidade de recursos de metaforicidade que determinariam a possibilidade de as metáforas, em um certo evento discursivo, serem reconhecidas como tais (MÜLLER, 2008). Em seguida, argumenta-se que são as expectativas relativas à ocorrência de metáforas que emergem do nosso frame de cada gênero que regulam o uso desses recursos. É essa linha de raciocínio que permite se compreender, por fim, a metaforicidade - isto é, a possibilidade de as metáforas serem reconhecidas como tais - como um aspecto antes do gênero do que da linguagem metafórica per se. Na próxima seção, à guisa de conclusão, discutemse algumas consequências teóricas e práticas de se assumir essa noção de metaforicidade.

\section{CONCLUSÕES}

A proposta de uma noção de metaforicidade como sendo um aspecto do gênero promove uma reflexão muito interessante a respeito das fronteiras da própria metáfora. Essa noção sugere que as escolhas sobre quais expressões podem ser consideradas metafóricas ou não sempre vai depender das circunstâncias em que essas expressões estiverem sendo usadas. Uma primeira questão que a noção de metaforicidade como sendo um aspecto do gênero parece conseguir resolver, nesse sentido, é o impasse que se verifica entre a teoria conceptual (LAKOFF; JOHNSON, 1980; LAKOFF, 1993) e a opinião do falante comum a respeito da ocorrência de metáforas. Embora a teoria conceptual sustente que metáforas são onipresentes e inevitáveis - e muitas pesquisas dentro desse campo a corroborem (por exemplo, HALLYN, 2000; STEEN et al., 2010; FLUDERNIK, 2012), não é com quaisquer discursos que o falante associa a ocorrência delas (por exemplo, LAKOFF; JOHNSON, 1980; ORTONY, 1993 [1979]; KÖVECSES, 2010).

No entanto, ao se tomar a metaforicidade como sendo um aspecto do gênero, argumenta-se que, porque alguns gêneros são mais tolerantes a recursos da sua ativação do que outros e que, por isso, as suas metáforas podem ser mais facilmente reconhecidas, o falante imediatamente associa esse fenômeno àqueles gêneros e não a esses. Sendo assim, uma vez que o falante comum não seria, via de regra, capaz de perceber as metáforas em, digamos, uma bula de medicamento, ele não relaciona a sua ocorrência com esse gênero - mesmo que, segundo a teoria conceptual (LAKOFF; JOHNSON, 1980), seja muito provável que elas estejam lá.

A noção de metaforicidade como um aspecto do gênero parece ter algum impacto, ainda, sobre a maneira como são conduzidas as

23 Para efeitos desta discussão, prototipicidade (ROSCH, 1973, 1975) se refere à representação mental relativamente abstrata que reúne os traços - em geral, mais frequentes e mais salientes - que melhor representam exemplos concretos de uma dada categoria (ou, no caso deste trabalho, de um dado gênero). 
pesquisas que se ocupam das metáforas. A identificação e, sobretudo, a análise da linguagem metafórica, seja em quaisquer gêneros que forem, deveriam atentar, além do papel da ocorrência de eventuais metáforas no discurso, à função do seu reconhecimento nesses usos. Em um estudo sobre metáforas em textos jornalísticos - mais precisamente, editoriais e colunas de opinião -, por exemplo, Vereza (2007b) mostra que as expressões com maiores chances de serem reconhecidas como metafóricas - por meio de recursos específicos de ativação da sua metaforicidade - têm uma contribuição mais positiva à função argumentativa e persuasiva pretendida nesses tipos de discurso.

O que deve ficar claro, no final das contas, é que um diagnóstico preciso e, mais especificamente, uma determinação realmente consistente da metaforicidade e do papel da linguagem metafórica presente em um dado tipo de discurso passa a exigir, impreterivelmente, uma análise rigorosa do gênero com que esses textos se identificam. Nesse sentido, para se afirmar se as eventuais metáforas que ocorrem em um corpus qualquer seriam menos ou mais metafóricas ou, ainda, menos ou mais adormecidas, é necessário se lançar um olhar atento para os aspectos que prototipicamente caracterizam o seu tipo de discurso - como, por exemplo, onde ele geralmente se realiza, por quem e com que objetivos.

\section{REFERÊNCIAS}

AGÊNCIA SENADO. Eduardo Amorim faz alerta sobre situação da saúde em Sergipe. Senado Nortícias, Brasília, [n/a], nov. 2015. Disponível em: <http://www12.senado.leg.br/noticias>. Acesso em: 07 jun. 2016.

BABARCZY, Anna; BENCZE, Ildikó; FEKETE, István; SIMON, Eszter. The automatic identification of conceptual metaphors in Hungarian texts: a corpus-based analysis. Proceedings. In: INTERNATIONAL CONFERENCE ON LANGUAGE RESOURCES AND EVALUATION, 7., 2010, Malta. Anais... Malta: European Language Resources Association, 2010. p. 01-06.

BHATIA, Vijay. Worlds of written discourse: a genre-based view. Nova York / Londres: Continuum, 2004.

BLACK, Max. More about metaphor. In: ORTONY, Andrew (Ed.). Metaphor and thought. Cambridge: Cambridge University Press, 1993. p. 19-41.

BRASIL. Lei número 8.880, de 27 de maio de 1994. Dispõe sobre o Programa de Estabilização Econômica e o Sistema Monetário Nacional, institui a Unidade Real de Valor e dá outras providências. Coleção de leis da República Federativa do Brasil, Brasília, v. 186, n. 7, p. 2705-2711, 28 maio 1994.

CLOISEAU, Gilles. Defining semantic and prosodic tools for the analysis of live metaphor uses in spoken corpora. Cultura, Lenguaje y Representación, Castelló de la Plana, n. 5, p. 111-129, nov. 2007.

COMO aproveitar o real forte. Veja, São Paulo, v. 2004, ano 40, n. 15, capa, 18 abr. 2007. Disponível em: <http://veja.abril.com.br>. Acesso em: 30 out. 2014.

DEIGNAN, Aline. Deliberateness is not unique to metaphor: a response to Gibbs. Metaphor and the Social World, Amsterdam, v. 1, n. 1, p. 57-60, jun. 2011.

DELACROIX, Eugène. A Liberdade guiando o povo. 1830. 1 pintura.

DUNN, Jonathan. Gradient semantic intuitions of metaphoric expressions. Metaphor and Symbol, Oxford, v. 26, n. 1, p. 53-67, 2011.

EVANS, Vyvyan. A glossary of cognitive linguistics. Edimburgo: Edinburgh University Press, 2007. 
FREIRE, Vinicius. Temer, retrô e vintage. Folha de São Paulo, São Paulo, maio 2016. Disponível em: <http://wwwl.folha.uol.com.br/colunas/viniciustorres/>. Acesso em: 07 jun. 2016.

FLUDERNIK, Monika (Ed.). Beyond cognitive metaphor theory: perspectives on literary metaphor. Nova York: Routledge, 2012.

GIBBS, Raymond. The Cambridge handbook of metaphor and thought. Cambridge: Cambridge University Press, 2008.

GIBBS, Raymond. Are "deliberate" metaphors really deliberate: a question of human consciousness and action. Metaphor and the Social World, Amsterdam, v. 1, n. 1, p. 26-52, jun. 2011.

GIORA, Rachel. Understanding figurative and literal language: the graded salience hypothesis. Cognitive Linguistics, Berlim, v. 8, n. 3, p. 183-206, ago. 1997.

GOATLY, Andrew. The language of metaphors. Londres: Routledge, 1997.

GRADY, Joseph. Foundations of meaning: primary metaphors and primary scenes. 1997. 299 f. Tese (Doutorado em Linguística) - Departamento de Linguística, Universidade da Califórnia, Berkeley, 1997.

HALLYN, Fernand (Ed.). Metaphor and analogy in the sciences. Dordrecht: Kluwer Academics, 2000.

FERREIRA, Aurélio. Novo dicionário eletrônico Aurélio da língua portuguesa. Versão 5.11a. Curitiba: Positivo, 2004.

HOUAISS, Antônio; VILLAR, Mauro; FRANCO, Francisco. Dicionário Houaiss da língua portuguesa. Rio de Janeiro: Objetiva, 2009.

KÖVECSES, Zóltan. Metaphor: a practical introduction. Londres / Nova York: Oxford University Press, 2010.

LAKOFF, George. The contemporary theory of metaphor. In: ORTONY, Andrew (Ed.). Metaphor and thought. Cambridge: Cambridge University Press, 1993, p. 202-251.

LAKOFF, George; JOHNSON, Mark. Metaphors we live by. Chicago / Londres: The University of Chicago Press, 1980.

LEONE, Shirley. Metaphoricity, language, and mind. 1980. 152 f. Dissertação (Mestrado em Psicologia do Desenvolvimento) Departamento de Artes, The Union for Experimenting Colleges and Universities, Cincinnati, 1980.

MÜLLER, Cornelia. Metaphors dead and alive, sleeping and awaking: a dynamic view. Chicago: The University of Chicago Press, 2008.

MÜLLER, Cornelia. Are "deliberate" metaphors really deliberate: a question of human consciousness and action. Metaphor and the Social World, Amsterdam, v. 1, n. 1, p. 61-66, jun. 2011.

ORTONY, Andrew (Ed.). Metaphor and thought. Cambridge: Cambridge University Press, 1993.

OXFORD BRITISH AND WORLD ENGLISH DICTIONARY. Londres / Nova York: Oxford University Press, 2015. Disponível em: $<$ http://www.oxforddictionaries.com/>. Acesso em: 11 dez. 2015.

PALTRIDGE, Brian. Working with genre: a pragmatic perspective. Journal of Pragmatics, Amsterdam, v. 24, n. 4, p. 393-406, out. 1995. 
PAUWELS, Paul. Levels of metaphorization: the case of "put". In: GOOSSENS, Louis et al. (Org.). By word of mouth: metaphor, metonymy and linguistic action in a cognitive perspective. Amsterdam: John Benjamins, 1995. p. 125-158.

PRAGGLEJAZ. MIP: a method for identifying metaphorically used words in discourse. Metaphor and Symbol, Oxford, v. 22, n. 1, p. 1-39, 2007.

RICHARDS, Ivor. The philosophy of rhetoric. Londres / Nova York: Oxford University Press, 1936.

ROSCH, Eleanor. On the internal structure of perceptual and semantic categories. In: MOORE, Timothy (Ed.). Cognitive development and the acquisition of language. Nova York: Academic, 1973. p. 111-144.

ROSCH, Eleanor. Cognitive representations of semantic categories. Journal of Experimental Psychology, Washington, v. 104, n. 3 , p. 192-233, set. 1975.

SANTAYANNA, Mauro. O Brasil deve, mas está longe de estar quebrado. Jornal do Brasil, Rio de Janeiro, set. 2015. Disponível em: <http://www.jb.com.br/sociedade-aberta/noticias/>. Acesso em: 07 jun. 2016.

STEEN, Gerard. Can discourse properties of metaphor affect metaphor recognition? Journal of Pragmatics, Amsterdam, v. 36, n. 7, p. 1295-1313, jul. 2004.

STEEN, Gerard. Metaphor in applied linguistics: four cognitive approaches. D.E.L.T.A., São Paulo, v. 22, n. especial, p. 21-44, 2006.

STEEN, Gerard. What does "really deliberate" really means: more thoughts on metaphor and consciousness. Metaphor and the Social World, Amsterdam, v. 1, n. 1, p. 53-56, jun. 2011a.

STEEN, Gerard. Genre between the humanities and the sciences. In: CALLIES, Marcus; KELLER, Wolfram; LOHÖFER, Astrid (Ed.). Bi-directionality in the cognitive sciences. Amsterdam: John Banjamins, 2011b. p. 21-41.

STEEN, Gerard et al. A method for linguistic metaphor identification: from MIP to MIPVU. Amsterdam / Filadélfia: John Benjamins, 2010.

VEREZA, Solange. Literalmente falando: sentido literal e metáfora na metalinguagem. Niterói: Editora da Universidade Federal Fluminense, 2007a.

VEREZA, Solange. Metáfora e argumentação: uma abordagem cognitivo-discursiva. Linguagem em (Dis)curso, Tubarão, v. 7, n. 3, p. 487-506, 2007b. 